Developments in Paleoenvironmental Research

VOLUME 1 
Tracking Environmental Change Using Lake Sediments. Volume 1: Basin Analysis, Coring, and Chronological Techniques 


\title{
Tracking Environmental Change Using Lake Sediments Volume 1:
}

\section{Basin Analysis, Coring, and Chronological Techniques}

\author{
Edited by \\ William M. Last \\ Department of Geological Sciences, \\ University of Manitoba \\ and \\ John P. Smol \\ Department of Biology, \\ Queen's University
}

KLUWER ACADEMIC PUBLISHERS

NEW YORK, BOSTON, DORDRECHT, LONDON, MOSCOW 
eBook ISBN: $\quad$ 0-306-47669-X

Print ISBN: $\quad$ 0-7923-6482-1

(C)2002 Kluwer Academic Publishers

New York, Boston, Dordrecht, London, Moscow

Print @2001 Kluwer Academic Publishers

Dordrecht

All rights reserved

No part of this eBook may be reproduced or transmitted in any form or by any means, electronic, mechanical, recording, or otherwise, without written consent from the Publisher

Created in the United States of America

Visit Kluwer Online at:

http://kluweronline.com

and Kluwer's eBookstore at:

http://ebooks.kluweronline.com 


\section{DEDICATION}

Dedicated to Prof. B. E. Berglund, whose edited volume Handbook of Holocene Palaeoecology and Palaeohydrology has guided researchers for over 15 years. 


\section{CONTENTS}

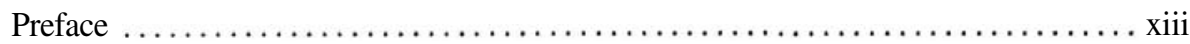

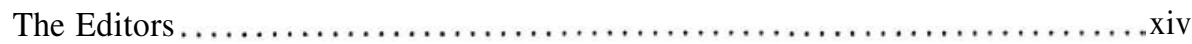

Aims \& Scope of Developments in Paleoenvironmental Research Book Series .... xv

Editors and Board of Advisors of Developments in Paleoenvironmental

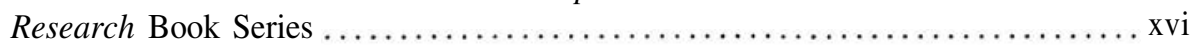

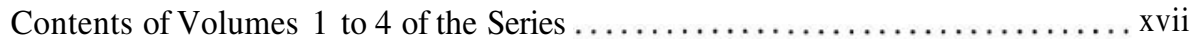

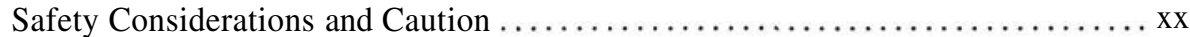

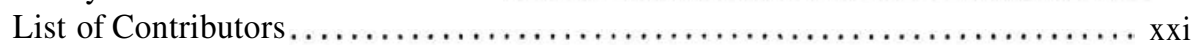

1. An introduction to basin analysis, coring, and chronological techniques used in paleolimnology. William M. Last \& John P. Smol ....................... 1

\section{Part I: Basin Analysis Techniques}

2. Applications of seismic sequence stratigraphy in lacustrine basins.

Christopher A. Scholz ........................................ 7

Introduction

Seismic sequence stratigraphy applied to lake basins

Theoretical considerations of the seismic reflection method

Practical considerations, instrumentation and scales of observation

Sequence stratigraphic interpretation of lacustrine seismic reflection data

Summary

Acknowledgments

References

3. Ground-penetrating radar applications in paleolimnology.

Brian J. Moorman .

Introduction

Ground-Penetrating radar theory

Data acquisition

Data processing and interpretation

Applications

Summary

Acknowledgments

References 
4. Shoreline and basin configuration techniques in paleolimnology.

Dorothy Sack

Introduction

Coastal landform nomenclature

Shoreline identification

Shoreline reconstruction

Water body delineation

Chronologic considerations

Paleoclimatic reconstruction

Other applications

Conclusions and future outlook

Summary

Acknowledgments

References

\section{Part II: Core Acquisition, Archiving, and Logging Techniques}

5. Sediment core collection and extrusion.

John R. Glew, John P. Smol \& William M. Last

Introduction

Aim of good core recovery

Nature of lacustrine sediment

Nature of the sampling process

Effects of frictional and deformational forces on the sediment sample

Major types of sampling equipment

Open-barrel and gravity corers

Box corers and dredges

Piston coring devices driven by rods

Cable-operated piston corers

Chamber-type samplers

Freeze samplers

Vibracorers

Other corers and modifications

Percussion or hammer corers

Modifications to gravity coring equipment

Pneumatic corers

Core catching devices

Extruding and subsampling equipment

Summary

Acknowledgements

References 
6. Coring and drilling equipment and procedures for recovery of long lacustrine sequences. Suzanne A. G. Leroy \& Steve M. Colman ........................ 107

Introduction

Coring and drilling technology and operation from lake surfaces

Adaptation from ODP technology and the development of a new drilling rig

Drilling systems

Drilling platforms and positioning

Procedure recommendations

Inventory of drilling equipment

A brief comparison of the techniques

Environmental protection and safety issues

Conclusion

Summary

Acknowledgements

Appendix 1: Contact addresses

References

7. Sediment logging techniques.

Bernd Zolitschka, Jens Mingram, Sjerry van der Gaast,

J. H. Fred Jansen \& Rudolf Naumann

Introduction

Brief history of use and development of logging techniques

Core logging devices

Conclusion and future directions

Summary

Acknowledgements

References

8. Logging of magnetic susceptibility.

Norbert R. Nowaczyk

Introduction

Different methods of logging magnetic susceptibility

Examples

Summary

Acknowledgements

References

\section{Part III Chronostratigraphic Techniques}

9. Chronostratigraphic techniques in recent sediments.

P. G. Appleby 
Introduction

Origins of fallout radionuclides

Sediment records of fallout radionuclides

Simple ${ }^{210} \mathrm{~Pb}$ dating models

Vertical mixing

Numerical techniques

Radiometric techniques

Discussion

Summary

Acknowledgements

References

10. ${ }^{14} \mathrm{C}$ chronostratigraphic techniques in paleolimnology.

Svante Björck \& Barbara Wohlfarth ............................... 205

Introduction

Methods and problems

Radiocarbon-dating different fractions of the sediment

${ }^{14} \mathrm{C}$ as a chronostratigraphic tool

Dating of long (old) stratigraphies

High resolution dating and wiggle matching

${ }^{14} \mathrm{C}$ dating versus absolute dating techniques of lacustrine sediments

Concluding remarks

Summary

Useful www addresses

Acknowledgements

References

11. Varve chronology techniques.

Scott Lamoureux.

Introduction

Methods

Summary and future directions

Acknowledgements

References

12. Luminescence dating.

Olav B. Lian \& D. J. Huntley

Introduction

The mechanism responsible for luminescence

Dating and estimation of the paleodose

Thermoluminescence dating

Optical dating

Evaluating the environmental dose rate 
Sample collection and preparation

What types of depositional environments are suitable for luminescence dating?

What can lead to an inaccurate optical age?

Summary

Acknowledgements

References

13. Electron spin resonance (ESR) dating in lacustrine environments.

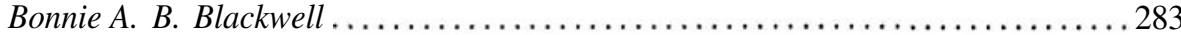

Introduction

Principles of ESR analysis

Sample collection

ESR analysis

ESR microscopy and other new techniques

Applications and datable materials in limnological settings

Summary

Acknowledgements

References

14. Use of paleomagnetism in studies of lake sediments.

John King \& John Peck.

Introduction

Recording fidelity of geomagnetic behavior by sediments

Field and laboratory methods

Holocene SV records

Magnetostratigraphic studies of Neogene lake sediments

Excursions, short events and relative paleointensity

Conclusions

Summary

References

15. Amino acid racemization (AAR) dating and analysis in lacustrine environments.

Bonnie A. B. Blackwell.

Introduction

Racemization and epimerization

Sampling protocols

AAR analysis

AAR dating

Dating and aminostratigraphic correlation in lacustrine environments

Paleoenvironmental analyses in lacustrine environments

Summary

Acknowledgements

References 
16. Tephrochronology.

C. S. M. Turney \& J. J. Lowe

Introduction

Mechanisms of tephra horizons

Detection of tephra horizons

Extraction of tephra shards

Correlation and dating of tephras: building a tephrochronological framework Applications of tephrochronology

Summary

Acknowledgements

References

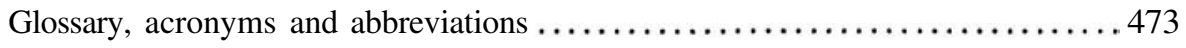

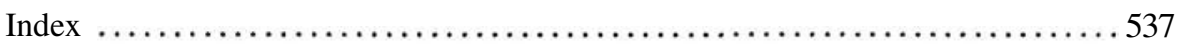




\section{PREFACE}

The explosive growth of paleolimnology over the past two decades has provided impetus for the publication of this series of monographs detailing the numerous advances and new techniques being applied to the interpretation of lake histories. This is the first volume in the series and deals mainly with the acquisition and archiving of cores, chronological techniques, and large-scale basin analysis methods. Volume 2 (Last \& Smol, 2001) examines the physical and geochemical parameters and methods; Volumes 3 and 4 (Smol et al., $2001 \mathrm{a}, \mathrm{b})$ provide a comprehensive overview of the many biological techniques that are used in paleolimnology. A fifth volume that is currently being prepared (Birks et al., in preparation) examines statistical and data handling methods. It is our hope that these monographs will provide sufficient detail and breadth to be useful handbooks for both seasoned practitioners as well as newcomers to the area of paleolimnology. These books should also be useful to non-paleolimnologists (e.g., limnologists, environmental scientists, archeologists, palynologists, geographers, geologists, etc.) who continue to hear and read about paleolimnology, but have little chance to explore the vast and sometimes difficult to access journal-based reference material for this rapidly expanding field. Although the chapters in these volumes target mainly lacustrine settings, many of the techniques described can also be readily applied to fluvial, glacial, marine, estuarine, and peatland environments.

The 16 chapters in this volume are organized into three major parts. The four chapters in Part I provide an overview of the most common, large-scale basin analysis methods. Part II summarizes the suite of sample acquisition, archiving and logging techniques routinely used in paleolimnology. The third and largest part of this book includes eight chapters summarizing chronostratigraphic techniques. Following this is a comprehensive glossary and list of acronyms and abbreviations.

Many people have helped with the planning, development, and final production of this volume. In addition to the hard work provided by the authors of these contributions, this publication benefitted from the technical reviews furnished by our scientific colleagues, many of whom remain anonymous. Each chapter was critically examined by two external referees as well as the editors. In order to assure readability for the major target audience, we asked many of our graduate students to also examine selected chapters; their insight and questioning during the reviewing and editorial process are most gratefully acknowledged. The staff of the Environmental, Earth and Aquatic Sciences Division of Kluwer Academic Publishers are commended for their diligence in production of the final presentation. In particular, we would also like to thank Ad Plaizier, Anna Besse-Lototskaya (Publishing Editor, Aquatic Science Division), and Rene Mijs (former Publishing Editor, Biosciences Division) for their long-term support of this new series of monographs and their interest in paleoenvironmental research. Finally, we would like to thank our respective universities and colleagues for support and encouragement during this project. 


\section{THE EDITORS}

William M. Last is a professor in the Department of Geological Sciences at University of Manitoba (Winnipeg, Manitoba, Canada) and is co-editor of the Journal of Paleolimnology.

John P. Smol is a professor in the Biology Department at Queen's University (Kingston, Ontario, Canada), with a cross-appointment at the School of Environmental Studies. He co-directs the Paleoecological Environmental Assessment and Research Lab (PEARL). Professor Smol is co-editor of the Journal of Paleolimnology and holds the Canada Research Chair in Environmental Change. 


\section{AIMS AND SCOPE OF DEVELOPMENTS IN PALEOENVIRONMENTAL RESEARCH SERIES}

Paleoenvironmental research continues to enjoy tremendous interest and progress in the scientific community. The overall aims and scope of the Developments in Paleoenvironmental Research book series is to capture this excitement and document these developments. Volumes related to any aspect of paleoenvironmental research, encompassing any time period, are within the scope of the series. For example, relevant topics include studies focused on terrestrial, peatland, lacustrine, riverine, estuarine, and marine systems, ice cores, cave deposits, palynology, isotopes, geochemistry, sedimentology, paleontology, etc. Methodological and taxonomic volumes relevant to paleoenvironmental research are also encouraged. The series will include edited volumes on a particular subject, geographic region, or time period, conference and workshop proceedings, as well as monographs. Prospective authors and/or editors should consult the series editors for more details. The series editors also welcome any comments or suggestions for future volumes. 


\section{EDITORS AND BOARD OF ADVISORS OF DEVELOPMENTS IN PALEOENVIRONMENTAL RESEARCH BOOK SERIES}

\section{Series Editors:}

John P. Smol

Paleoecological Environmental Assessment and Research Lab (PEARL)

Department of Biology

Queen's University

Kingston, Ontario, K7L 3N6, Canada

e-mail: SmolJ@BIOLOGY.QueensU.Ca

William M. Last

Department of Geological Sciences

University of Manitoba

Winnipeg, Manitoba R3T 2N2, Canada

e-mail: WM_Last@UManitoba.ca

\section{Advisory Board:}

Professor Raymond S. Bradley

Department of Geosciences

University of Massachusetts

Amherst, MA 01003-5820 USA

e-mail: rbradley@climate1.geo.umass.edu

Professor H. John B. Birks

Botanical Institute

University of Bergen

Allégaten 41

N-5007 Bergen

Norway

e-mail:John.Birks@bot.uib.no

Dr. Keith Alverson

Science Officer

IGBP-PAGES International Project Office

Barenplatz 2

3011 Bern

Switzerland

e-mail: alverson@pages.unibe.ch 


\section{CONTENTS OF VOLUMES 1 TO 4 OF THE SERIES}

\section{Contents of Volume 1: Tracking Environmental Change Using Lake Sediments: Basin Analysis, Coring, and Chronological Techniques.}

An introduction to basin analysis, coring, and chronological techniques used in paleolimnology. William M. Last \& John P. Smol

Applications of seismic sequence stratigraphy in lacustrine basins. Christopher A. Scholz

Ground penetrating radar applications in paleolimnology. Brian J. Moorman

Shoreline and basin configuration techniques in paleolimnology. Dorothy Sack

Sediment core collection and extrusion. John R. Glew, John P. Smol \& William M. Last

Coring and drilling equipment and procedures for recovery of long lacustrine sequences. Suzanne A. G. Leroy \& Steve M. Colman

Sediment logging techniques. Bernd Zolitschka, Jens Mingram, Sjerry van der Gaast, J. H. Fred Jansen \& Rudolf Naumann

Logging of magnetic susceptibility. Norbert R. Nowaczyk

Chronostratigraphic techniques in recent sediments. P. G. Appleby

${ }^{14} \mathrm{C}$ chronostratigraphic techniques in paleolimnology. Svante Björck \& Barbara Wohlfarth

Varve chronology techniques. Scott Lamoureux

Luminescence dating. Olav B. Lian \& D. J. Huntley

Electron spin resonance (ESR) dating in lacustrine environments. Bonnie A. B. Blackwell

Use of paleomagnetism in studies of lake sediments. John King \& John Peck

Amino acid racemization (AAR) dating and analysis in lacustrine environments. Bonnie A. B. Blackwell

Tephrochronology. C. S. M. Turney \& J. J. Lowe

Glossary, Acronyms and Abbreviations

Subject Index

Contents of Volume 2: Tracking Environmental Change Using Lake Sediments: Physical and Geochemical Methods.

An introduction to physical and geochemical methods used in paleolimnology.

William M. Last \& John P. Smol 
Recognition and analysis of bedding and sediment fabric features. Alan E. S. Kemp, Jean Dean, Richard B. Pearce \& Jennifer Pike

Image analysis techniques. Timo Saarinen \& Gunilla Petterson

Textural analysis of lake sediments. William M. Last

Inorganic geochemical methods in paleolimnology. J. F. Boyle

Mineralogical analysis of lake sediments. William M. Last

Fluid inclusions in paleolimnological studies of chemical sediments. Tim Lowenstein \& Sean T. Brennan

Application of mineral magnetic techniques to paleolimnology. Per Sandgren \& Ian Snowball

Sediment organic matter. Philip A. Meyers \& Jane L. Teranes

Paleolimnological methods and applications for persistent organic pollutants. Jules M. Blais \& Derek C. G. Muir

Near-Infrared spectrometry (NIRS) in paleolimnology. Tom Korsman, Eigil Dåbakk, Mats B. Nilsson \& Ingemar Renberg

Fly-ash particles. Neil Rose

Application of stable isotope techniques to inorganic and biogenic carbonates. Emi Ito

Carbon and oxygen isotope analysis of lake sediment cellulose: methods and applications. Brent B. Wolfe, Thomas W. D. Edwards,

Kristina R. M. Beuning \& Richard J. Elgood

Nitrogen isotopes in palaeolimnology. Michael R. Talbot

Glossary, Acronyms and Abbreviations

Subject Index

Contents of Volume 3: Tracking Environmental Change Using Lake Sediments: Terrestrial, Algal, and Siliceous Indicators.

Using biology to study long-term environmental change. John. P. Smol, H. John B. Birks \& William M. Last

Pollen. K. D. Bennett \& K. J. Willis

Conifer stomata. Glen M. MacDonald

Plant macrofossils. Hilary H. Birks

Charcoal as a fire proxy. Cathy Whitlock \& Chris Larsen

Non-pollen palynomorphs. Bas van Geel 
Protozoa: testate amoebae. Louis Beyens \& Ralf Meisterfeld

Diatoms. Richard W. Battarbee, Laurence Carvalho, Vivienne J. Jones, Roger J. Flower, Nigel G. Cameron, Helen Bennion \& Stephen Juggins

Chrysophyte scales and cysts. Barbara A. Zeeb \& John P. Smol

Ebridians. Atte Korhola \& John P. Smol

Phytoliths. Dolores R. Piperno

Freshwater sponges. Thomas M. Frost

Siliceous protozoan plates and scales. Marianne S. V. Douglas \& John P. Smol

Biogenic silica. Daniel J. Conley \& Claire L. Schelske

Sedimentary pigments. Peter R. Leavitt \& Dominic A. Hodgson

Glossary, Acronyms and Abbreviations

Subject Index

\section{Contents of Volume 4: Tracking Environmental Change Using Lake Sediments: Zoological Indicators.}

Zoological indicators in lake sediments: an introduction. John. P. Smol, H. John B. Birks \& William M. Last

Cladocera and other branchiopod crustaceans. Atte Korhola \& Milla Rautio

Midges: Chironomidae and related Diptera. Ian R. Walker

Coleoptera and Trichoptera. Scott A. Elias

Oribatid mites. Torstein Solhøy

Bryozoan statoblasts. Donna R. Francis

Ostracoda. Jonathan A. Holmes

Freshwater molluscs. Barry B. Miller \& Michael J. S. Tevesz

Fish. W. P. Patterson \& G. R. Smith

Glossary, Acronyms and Abbreviations

Subject Index 


\section{SAFETY CONSIDERATIONS AND CAUTION}

Paleolimnology has grown into a vast scientific pursuit with many branches and subdivisions. It should not be surprising, therefore, that the tools used by paleolimnologists are equally diverse. Virtually every one of the techniques described in this book requires some familiarity with standard laboratory or field safety procedures. In some of the chapters, the authors have made specific reference to appropriate safety precautions; others have not. The responsibility for safe and careful application of these methods is yours. Never underestimate the personal risk factor when undertaking either field or laboratory investigations. Researchers are strongly advised to obtain all safety information available for the techniques they will be using and to explicitly follow appropriate safety procedures. This is particularly important when using strong acids, alkalies, or oxidizing reagents in the laboratory or many of the analytical and sample collection/preparation instruments described in this volume. Most manufacturers of laboratory equipment and chemical supply companies provide this safety information, and many Internet and other library resources contain additional safety protocols. Researchers are also advised to discuss their procedures with colleagues who are familiar with these approaches, and so obtain further advice on safety and other considerations.

The editors and publisher do not necessarily endorse or recommend any specific product, procedure, or commercial service that may be cited in this publication. 


\section{LIST OF CONTRIBUTORS}

P. G. Appleby

Department of Mathematical Sciences

University of Liverpool

P. O. Box 147

Liverpool, L69 3BX, UK

e-mail: appleby@liverpool.ac.uk

Svante Björck

Department of Quaternary Geology

Lund University

Tornavägen 13

SE-223 63 Lund, Sweden

e-mail: svante.bjorck@geol.lu.se

Bonnie A. B. Blackwell

Department of Chemistry

Williams College

Williamstown, MA 01267 USA

e-mail: Bonnie.A.B.Blackwell@williams.edu

Steve M. Colman

U.S. Geological Survey

384 Woods Hole Rd

Woods Hole, MA 02543, USA

e-mail: scolman@usgs.gov

John R. Glew

Paleoecological Environmental Assessment and Research Lab (PEARL)

Department of Biology

Queen's University

Kingston, Ontario, K7L 3N6, Canada

e-mail: glewj@biology.queensu.ca

D. J. Huntley

Department of Physics

Simon Eraser University

Burnaby, B.C., V5A 1S6, Canada

e-mail: huntley@sfu.ca

J. H. Fred Jansen

Netherlands Institute for Sea Research

P.O. Box 59

NL-1790 AB Den Burg (Texel)

The Netherlands

e-mail: jansen@nioz.nl 
xxii

John King

Graduate School of Oceanography

University of Rhode Island

Narragansett, RI 02882-1197, USA

e-mail: jking@gso.uri.edu

Scott Lamoureux

Department of Geography

Queen's University

Kingston, Ontario, K7L 3N6, Canada

e-mail: lamoureux@lake.geog.queensu.ca

William M. Last

Department of Geological Sciences

University of Manitoba

Winnipeg, Manitoba, R3T 2N2, Canada

e-mail: WM_Last@UManitoba.ca

Suzanne A. G. Leroy

Department of Geography and Earth Sciences

Brunel University

Uxbridge UB8 3PH, Middlesex, UK

e-mail: suzanne.leroy@brunel.ac.uk

Olav B. Lian

Department of Geography

Royal Holloway, University of London

Egham, Surrey, U.K. TW20 0EX

e-mail:olav.lian@ rhul.ac.uk

J. J. Lowe

Centre for Quaternary Research

Geography Department

Royal Holloway, University of London

Egham, Surrey, TW20 0EX, UK

e-mail: J.Lowe@rhbnc.ac.uk

Jens Mingram

GeoForschungsZentrum Potsdam

PB 3.3 - Sedimentation and Basin Analysis

Telegrafenberg, D-14473 Potsdam, Germany

e-mail: ojemi@gfz-potsdam.de 
Brian Moorman

Earth Science Program

University of Calgary

2500 University Drive N.W.

Calgary, AB, T2N 1N4, Canada

e-mail:moorman@ucalgary.ca

\section{Rudolf Naumann}

GeoForschungsZentrum Potsdam

PB 4.2 - Material Properties and Transport Processes

Telegrafenberg, D-14473 Potsdam, Germany

e-mail: rudolf@gfz-potsdam.de

Mats B. Nilsson

Department of Forest Ecology

Swedish University of Agricultural Sciences

SE-901 83 Umeå, Sweden

e-mail: Mats.B.Nilsson@sek.slu.se

Norbert R. Nowaczyk

GeoForschungsZentrum Potsdam

Projektbereich 3.3

"Sedimente und Beckenbildung"

Telegrafenberg, 14473 Potsdam, Germany

e-mail:nowa@gfz-potsdam.de

John Peck

Department of Geology

University of Akron

Akron, OH, 44325-4101, USA

e-mail:.jpeck@uakron.edu

Dorothy Sack

Department of Geography

122 Clippinger Labs

Ohio University

Athens, OH 45701 USA

e-mail: sack@oak.cats.ohiou.edu

Christopher A. Scholz

Department of Earth Sciences

Syracuse University

Syracuse, New York, 13152, USA

e-mail: cascholz@syr.edu 
xxiv

John P. Smol

Paleoecological Environmental Assessment and Research Lab (PEARL)

Department of Biology

Queen's University

Kingston, Ontario, K7L 3N6, Canada

e-mail: SmolJ@BIOLOGY.QueensU.Ca

C. S. M. Turney

School of Archaeology and Palaeoecology

Queen's University

Belfast, BT7 1NN UK

e-mail:c.turney@qub.ac.uk

Sjerry van der Gaast

NIOZ, P.O. Box 59

NL-1790 AB Den Burg (Texel), The Netherlands

e-mail: gaast@nioz.nl

Barbara Wohlfarth

Department of Quaternary Geology

Lund University

Tornavägen 13

S-223 63 Lund, Sweden

e-mail: Barbara.Wohlfarth@geol.lu.se

Bernd Zolitschka

Geomorphologie und Polarforschung (GEOPOL)

Institut für Geographie

Universitaet Bremen

Celsiusstr. FVG-M

D-28359 Bremen, Germany

e-mail:zoli@uni-bremen.de 